\title{
Group B Streptococcus colonization in pregnancy: prevalence and prevention strategies of neonatal sepsis
}

\author{
Alma-Verena Rausch', Ariane Gross', Sara \\ Droz $^{2}$, Thomas Bodmer ${ }^{2}$ and Daniel V. Surbek ${ }^{1, *}$ \\ ${ }^{1}$ Department of Obstetrics and Gynecology, Inselspital, \\ Bern University Hospital, and University of Bern, \\ Switzerland \\ 2 Institute of Infectious Diseases, Inselspital, Bern \\ University Hospital, and University of Bern, \\ Switzerland
}

\begin{abstract}
Early onset neonatal sepsis due to Group B streptococci (GBS) is responsible for severe morbidity and mortality of newborns. While different preventive strategies to identify women at risk are being recommended, the optimal strategy depends on the incidence of GBS-sepsis and on the prevalence of anogenital GBS colonization. We therefore aimed to assess the Group B streptococci prevalence and its consequences on different prevention strategies.

We analyzed 1316 pregnant women between March 2005 and September 2006 at our institution. The prevalence of GBS colonization was determined by selective cultures of anogenital smears. The presence of risk factors was analyzed. In addition, the direct costs of screening and intrapartum antibiotic prophylaxis were estimated for different preventive strategies.

The prevalence of GBS colonization was $21 \%$. Any maternal intrapartum risk factor was present in $37 \%$. The direct costs of different prevention strategies have been estimated as follows: risk-based: 18,500 CHF/1000 live births, screening-based: 50,110 CHF/1000 live births, combined screening- and risk-based: 43,495/1000 live births.

Strategies to prevent GBS-sepsis in newborn are necessary. With our colonization prevalence of $21 \%$, and the intrapartum risk profile of women, the screening-based approach seems to be superior as compared to a riskbased approach.
\end{abstract}

\footnotetext{
${ }^{*}$ Corresponding author:

Prof. Daniel Surbek, MD

Department of Obstetrics and Gynecology

University Hospital Bern

Effingerstr. 102

3010 Bern/Switzerland

Tel.: +4131632 1103

Fax: +41316321105

E-mail: daniel.surbek@insel.ch
}

Keywords: Costs; GBS-sepsis; intrapartum antibiotics; prevalence; screening and risk factor based strategies.

\section{Introduction}

Intrapartum vaginal presence of Group B Streptococcus (Streptococcus agalactiae, GBS), a facultative gram-positive diplococcus, can cause severe neonatal infections including sepsis, pneumonia and meningitis, which generally occur within the first week of life (early-onset disease) or after seven days (late-onset disease) [6, 15]. Infections with GBS have been recognized as the leading cause of early-onset neonatal sepsis with significant mortality. Epidemiologic studies in the pre-prevention era revealed an incidence of 1-3 cases of early-onset neonatal GBS per 1000 with a case-fatality rate of $20-50 \%$ $[22,28]$. The risk of colonization of a neonate born to a colonized mother is between 40 and $70 \%[5,10,13]$ and $1-2 \%$ of these colonized infants will develop an earlyonset disease. At any given time, between $10-30 \%$ of women in the United States and between $5-15 \%$ in Europe are colonized with GBS [24, 26, 27]. Thus, in the 1980s intensive research started with the goal to find a way of preventing GBSs vertical transmission. Randomized controlled trials showed that intrapartum antibiotic treatment of colonized women prevents early-onset neonatal sepsis with $80 \%$ effectiveness [8]. However, because no rapid GBS detection test with a high sensitivity and specificity exists to date, it was a matter of debate how to identify women who benefit from intrapartum antibiotic prophylaxis. Guidelines for intrapartum prophylaxis of neonatal GBS infections were issued in 1996 by the American College of Obstetricians and Gynecologists (ACOG) and the centers of disease control (CDC) [4], and in 1997 by the American Academy of Pediatrics (AAP) [1].

These recommendations were that intrapartum antibiotic prophylaxis is given based either on a risk- or on a screening-based approach. A risk-based approach is adapted from the presence of at least one maternal risk factor. Risk-factors associated with neonatal GBS disease are: gestational age at delivery $<37$ weeks, intrapartum temperature $\geq 38^{\circ} \mathrm{C}\left(100.4^{\circ} \mathrm{F}\right)$, rupture of membranes for $\geq 18 \mathrm{~h}$ ( $\geq 12 \mathrm{~h}$ ), GBS bacteriuria during the current pregnancy or a previous delivery of a child affected by early-onset GBS sepsis. The screeningbased approach includes universal screening of all pregnant women for GBS colonization between 35 and 
37 weeks' gestation and offering intrapartum antibiotics to all colonized women irrespective of other risk factors except GBS bacteruria during their current pregnancy, or a previous birth of an infant affected by early-onset GBS disease. An alternative strategy, which aims to reduce the number of women receiving intrapartum antibiotics by combining these two strategies, was also recommended by the Canadian Task Force Committee [23]. Only women screened positive for GBS and having one of the above-mentioned intrapartum risk factors receive prophylaxis with antibiotics during labor. In a previous study, we showed the efficacy of such a strategy [19].

In 2002 these guidelines were revised by the CDC, $A A P$ and $A C O G$ due to new data showing superior effectiveness of the screening-based strategy [21]. The German Association for Gynecology and Obstetrics (DGGG) [16] and the Swiss Society for Gynecology and Obstetrics (SGGG) [25] adopted these suggestions, whereas the British Royal College of Obstetricians and Gynaecologists (RCOG) rejected it due to increased costs, potential increase in penicillin-induced anaphylaxis and microbial resistance [14].

In order to achieve the optimal strategy in a population, updated epidemiological data about the prevalence of GBS carriers, about the intrapartum risk-profile of women, and also about the incidence of early-onset GBSsepsis are required. Based on the social, economical and local settings, results from these surveys differ to a significant extent. The purpose of this study was therefore to establish a detailed epidemiological dataset within our own population with respect to GBS carrier status, risk factors during birth and direct costs of different prevention strategies. In the future these data might be used as a historic control group after potential improvements in the diagnostic and/or therapeutic procedure.

\section{Material and methods}

We analyzed 1316 pregnant women in order to detect the prevalence of GBS colonization during pregnancy and the prevalence of intrapartum risk factors in GBS-colonized women between March 2005 and September 2006 at the University Women's Hospital Bern, Switzerland.

All pregnant women, who were screened for GBS during this time period $(n=1327)$ were included. Swabs were taken from the outer third of the vagina and the anal region, and analyzed by standard as well as selective bacterial cultures. Clinical data regarding risk factors were obtained from the patients charts. The patients' records of those who had a positive culture result were evaluated and the following variables noted: week of gestation at latest screening, method of delivery (spontaneous, vaginal-operative delivery, elective or secondary cesarean section), intrapartum risk factors, intrapartum antibiotic prophylaxis (IAP), and allergy reactions. Intrapartum risk factor are defined as prolonged ROM ( $>18 \mathrm{~h}$ ), preterm delivery ( $<37$ weeks' gestation) and maternal intrapartum fever $\left(38^{\circ} \mathrm{C}\right.$ or $\left.>100.3^{\circ} \mathrm{F}\right)$. Furthermore, GBS bacteruria during pregnancy and birth of a previous infant with GBS sepsis were recorded as risk factors. The illustration of risk factors and IAP comprises all women, who delivered spontaneously, by vaginal-operative delivery or secondary cesarean section $(n=163)$; women with elective cesarean section were excluded because there is uniform consensus that these women do not need GBS-prophylaxis due to an extremely low vertical transmission rate of GBS.

According to the CDC and ACOG guidelines, swabs were taken from both the vagina and the anal region and cultured in selective Todd-Hewitt broth supplemented with Nalixid acid and Colistin. The inoculated selective medium is incubated for 18-24 $\mathrm{h}$ and then subcultured onto sheep blood agar. Suspected colonies were tested by the CAMP assay. The sensitivity of the antenatal standard direct blood agar was defined as the proportion of women with positive GBS cultures in this standard culturing whose selective broth cultures were positive.

Finally, a cost analysis of antibiotic prophylaxis during birth was conducted. The cost of negative GBS culture, including material and staff time was estimated at $31 \mathrm{CHF}$. Due to additional tests, a positive culture was estimated at $72 \mathrm{CHF}$. The administration of intrapartum antibiotic prophylaxis was estimated at an average cost of $110 \mathrm{CHF}$, which includes two doses of antibiotics, the infusion device, intravenous fluids, and the cost of 30 min of a midwife's time. The cost-analyses of three different treatment strategies with intrapartum antibiotic prophylaxis were compared: (1) A risk-based strategy with administration of IAP only in presence of intrapartum risk factors. (2) A screening-based strategy with culture taken at 35-37 weeks of gestation and IAP given to all colonized women. (3) A combined screening/risk based strategy consisting of culture taken at 35-37 weeks of gestation and IAP only for GBS colonized women who, in addition, present at least one intrapartum risk factor.

\section{Results}

During the period between March 1, 2005 and September 30, 2006, 1316 pregnant women were screened for GBS by selective enrichment broth of rectovaginal swabs. A total of $1040(79 \%)$ patients had a negative culture result and in $276(21 \%)$ cases GBS carrier state was detected by selective enrichment broth.

At our institution, 201 pregnant women with positive culture results gave birth to an infant during this time period; in 75 cases patients attended our institution for a one-time emergency visit. In these cases follow-up and delivery was supervised by the patient's primary obstetrician. Of those who delivered at our institution, 163 (81\%) delivered spontaneously, by vaginal operation or by secondary cesarean section. In $102(62 \%)$ of these women, no intrapartum risk factor was identified, in 61 $(37 \%)$ at least one risk factor at birth had been identified (no risk factor known: $\mathrm{n}=102$ (62\%); 1 risk factor known: $\mathrm{n}=43$ (26\%), 2 risk factors known: $\mathrm{n}=16(10 \%), 3$ risk factors known: $n=2(1 \%), \leq 1$ risk factor known: 61 (37\%) (Table 1A).

Thus, pursuing a risk-based policy, 61 women out of the 163 colonized women with spontaneous, operative vaginal or non-elective cesarean delivery would have received IAP. 
Table 1 Intrapartum risk factor analysis in colonized women.

A) Division of risk factors

\begin{tabular}{|c|c|c|c|}
\hline No. of risk factors & Risk factors & n (163) & $\%$ \\
\hline 0 & & 102 & $63 \%$ \\
\hline$\geq 1$ & & 61 & $37 \%$ \\
\hline \multirow[t]{5}{*}{1} & Total & 43 & $26 \%$ \\
\hline & $\mathrm{ROM}>18 \mathrm{~h}$ & 18 & \\
\hline & Fever $>38^{\circ} \mathrm{C}$ & - & \\
\hline & Gestational age (G.A.) $<37$ weeks & 21 & \\
\hline & GBS-bacteruria during pregnancy & 4 & \\
\hline \multirow[t]{5}{*}{2} & Total & 16 & $10 \%$ \\
\hline & ROM $>18$ h + G.A. $<37$ weeks & 10 & \\
\hline & $\mathrm{ROM}>18 \mathrm{~h}+\mathrm{GBS}$ bacteruria & 2 & \\
\hline & Fever $>38^{\circ} \mathrm{C}+$ GBS-bacteruria & 1 & \\
\hline & G.A. $<37$ weeks + GBS-bacteruria & 3 & \\
\hline$\geq 3$ & $\begin{array}{l}\text { Total } \\
(\text { ROM }>18 \mathrm{~h}+\text { G.A. }<37 \text { weeks }+ \\
\left.\text { GBS-bacteruria }+ \text { fever }>38^{\circ} \mathrm{C}\right)\end{array}$ & 2 & $1 \%$ \\
\hline
\end{tabular}

B) Summary of risk factors (patient partially counted double)

\begin{tabular}{|c|c|c|}
\hline Risk factor & $\begin{array}{l}\text { Patient number } \\
\text { positive }\end{array}$ & $\begin{array}{l}\text { Percentage } \\
(n=163) \\
\end{array}$ \\
\hline $\mathrm{ROM}>18 \mathrm{~h}$ & 32 & $20 \%$ \\
\hline Fever $\geq 38^{\circ} \mathrm{C}$ & 3 & $2 \%$ \\
\hline Gestation age $<37$ weeks & 36 & $22 \%$ \\
\hline GBS-Bakteruria during pregnancy & 12 & $7 \%$ \\
\hline Having given birth to a child with early-onset GBS disease & 1 & $1 \%$ \\
\hline
\end{tabular}

Reviewing all intrapartum risk factors of these women in detail, $20 \%(n=32)$ of these women had ROM $>18 \mathrm{~h}$, $3 \%(n=3)$ temperature $>38^{\circ} \mathrm{C}, 22 \%(n=36)$ delivered prior to maturity, in $7 \%(n=12)$ GBS bacteruria during pregnancy was found and birth of previous neonate had been known in one case (Table 1B). Some institutions include ROM $>12 \mathrm{~h}$ instead of ROM $>18 \mathrm{~h}$ as a risk factor. Evaluating this in the overall risk-based analysis, no significant difference was found considering ROM $>12 \mathrm{~h}$ (62 women, 38\%, had at least one risk factor) compared to ROM > 18 h (61 women, 37\%, had at least one risk factor).

At our institution, a screening-based strategy is implemented, including IAP to all colonized women. As mentioned above, in 163 women with spontaneous, vaginal operative or secondary cesarean delivery, GBS-carrier state was verified. At the time of delivery, in 152 cases the culture result was actually known. In the remaining 11 cases, the culture result was available only after birth. One hundred and forty-five of these women received IAP (penicillin-based: $n=128$ women; clindamycin: $n=8$ women; erythromycin: $n=9$ women). Seven women did not receive any IAP for the following reasons: three women arrived at the hospital and delivered within one hour before antibiotics could be effectively given, two women had a subsequent negative GBS culture and for two women no reason for lack of IAP could be found.

Between the period of March 2005 until September 2006 one pregnant woman with verified GBS-coloniz- ation gave birth to a neonate affected by early-onset GBS-sepsis. This woman underwent a secondary cesarean delivery due to premature rupture of membranes $>18 \mathrm{~h}$ at $32 \mathrm{nd}$ week of gestation. Following hospitalization IAP with erythromycin due to penicillin-allergy was given. The GBS showed sensitivity to erythromycin in antibiotic resistance tests.

In 12 of 163 women (7.4\%), that delivered either spontaneously, by vaginal operation or by secondary cesarean section, allergy to penicillin was known. These women received erythromycin or clindamycin as IAP. No women developed anaphylaxis.

In Table 2, the calculation of direct costs on a cohort of 1000 pregnant women is shown. By implementation of a risk-based strategy, the cost of GBS prevention has been calculated (see Table 2) estimated at 18,500 CHF/ 1000 live birth, by a screening-based approach as high as $50,108 \mathrm{CHF} / 1000$ live birth and by a mixed screening and risk-based as high as 43,493 CHF/1000 live birth. The treatment costs of neonatal GBS disease not prevented by the respective strategies were not included in this analysis.

\section{Discussion}

Since the 1970s, GBS is increasingly recognized as a leading cause of serious neonatal infection with high morbidity and mortality. Consequently, prevention strat- 
Table 2 Analysis of direct costs.

\begin{tabular}{|c|c|c|c|}
\hline Prevention strategy & Cost of screening (CHF) & Cost of IAP (CHF) & Total cost \\
\hline Risk-based & & $\begin{array}{l}37 \% \text { at least } 1 \text { risk factor } \\
n=370 \\
\rightarrow 40,700 \mathrm{CHF}\end{array}$ & $40,700 \mathrm{CHF}$ \\
\hline Screening-based & $\begin{array}{l}\text { Screening of } 1000 \text { women: } \\
79 \%(n=790) \text { negative: } \\
24,490 \mathrm{CHF} \\
21 \%(\mathrm{n}=210) \text { positive: } \\
15,120 \mathrm{CHF} \\
\rightarrow 39,610 \mathrm{CHF}\end{array}$ & $\begin{array}{l}\text { IAP: } \\
21 \% \text { positive } \\
n=210 \\
\rightarrow 23,100 \mathrm{CHF}\end{array}$ & $62,710 \mathrm{CHF}$ \\
\hline $\begin{array}{l}\text { Combined risk and } \\
\text { screening-based }\end{array}$ & $\begin{array}{l}\text { Screening (as above) } \\
\rightarrow 39,610 \mathrm{CHF}\end{array}$ & $\begin{array}{l}\text { IAP: } \\
37 \% \text { out of } 21 \%(n=210) \\
\text { with } \geq 1 \text { risk factor } \\
\rightarrow 8,470 \mathrm{CHF}\end{array}$ & $48,080 \mathrm{CHF}$ \\
\hline
\end{tabular}

egies were developed and analyzed. Three main approaches have been adopted: a screening-based strategy, a risk-based strategy and a combination of both.

These strategies effectively prevent early-onset GBS disease in newborns [8, 22, 27]: an active, populationbased surveillance of the USA indicated a decline of the incidence of neonatal GBS sepsis by $70 \%$ from 1.7 to 0.5 cases per 1000 live births from 1989 to 1999 [21, 22]. However, disadvantages including costs, potential penicillin-induced anaphylaxis, and selection of resistant bacterial strains in newborns have led to controversies about the optimal preventive strategy [12, 21]. The RCOG guidelines, for example, do not recommend universal screening due to suboptimal cost-effectiveness ratio, lack of evidence of superiority of screening from randomized controlled trials, and a low incidence of GBS sepsis in the UK without screening (0.5 per 1000 newborns). Interestingly, GBS carrier data in pregnant women in the UK, which were cited in the guideline, originate from a study as old as 20 years. These recommendations have recently been challenged by a novel cost-effectiveness analysis in the UK [9]. The universal screening and IAP strategy has meanwhile been shown to be superior regarding early-onset neonatal GBS disease prevention as compared to the risk-based approach [21]: A 100\% implementation of a risk-based prevention strategy would have reduced the incidence from $0.5 / 1000$ to 0.44 / 1000 live births whereas a $100 \%$ implementation of a screening-based strategy would have led to a further reduction to $0.32 / 1000$ live births [21].

Thus, in 2002 the CDC revised their guidelines preferring a screening-based approach, which has been also adopted by the German societies for Obstetrics and Gynecology. Considering the notable increase in the proportion of women receiving antibiotics in labor with elevated risk of anaphylaxis and of bacterial resistance, the implementation of either preventive strategy might or might not be justified depending on the prevalence of maternal colonization, the intrapartum risk-profile and on the incidence of early-onset GBS disease [24] as well as on the cost profile.

The results from our population show that GBS colonization in pregnancy is observed with a prevalence of $21 \%$. In the US, prevalence of maternal colonization ranges from $10-30 \%$ and in most European countries from 10-20\% [27]. Other data from Switzerland report a prevalence of GBS colonization of $7.8 \%$ in Geneva [24] and $10 \%$ in Basel [26]. This lower prevalence may be due to regional differences or from different sampling or culturing techniques (vaginal samples alone or standard non-selective culture techniques yield a lower prevalence). Before the widespread use of IAP, the incidence of neonatal GBS disease in the US ranged from 2-3 cases per 1000 live births [7, 28]. In Europe, earlyonset GBS sepsis develops in $0.3-2 / 1000(\mathrm{~N})$; Swiss data report an incidence from $0.4 / 1000$ live births in Geneva [24] and 1/1000 in Basel [26], whereas at the University of Berne an incidence of 1.2/1000 has been recorded, concordant with a higher GBS colonization in pregnancy in Berne.

Our study further shows the risk profile of each woman with positive screening culture result. In $37 \%(n=61)$ of cases the women presented at least one intrapartum risk factor whereas no risk factor was recognized in $63 \%$ $(n=102)$ of positive tested women. Thus, following a riskbased approach as many as $63 \%(n=102)$ of colonized women were neglected in receiving IAP and only $37 \%$ of colonized women would have received intrapartum antibiotic prophylaxis. Therefore, risk-based IAP will not cover all colonized women and there will be more cases of early-onset disease considering that $40-70 \%$ newborns of colonized women are also infected with GBS and 1\% of these colonized neonatal develop neonatal GBS sepsis $[7,10,13]$.

As compared to other published studies, the prevalence of risk factors in our population is clearly higher than the $18-20 \%$ cited in other studies, indicating a risk 
profile typical for a tertiary care referral center (e.g., preterm delivery proportion of $22 \%$ ). Following the riskbased strategy in our population, more women would receive antibiotics for risk factors that might not be caused by GBS in every case. Due to uncertain GBS status the risk-based strategy does not follow exact administration of IAP yielding a higher risk of allergic reactions, antibiotic resistance and other complications whereas a screening-based strategy is much more reliable.

Nevertheless, the screening-based strategy shows slightly higher costs than the risk-based approach. Relating to 1000 women costs of a screening-based implementation are CHF 62,710, whereas costs in a risk-based program add up to $\mathrm{CHF} 40,700$. However, these calculations do not include treatment costs for newborn sepsis. To evaluate the screening program in terms of the total socio-economic burden, these consequential costs related to the treatment and care of septic newborns have to be balanced against the increased costs for the screening program. Prevention of a single case of newborn sepsis may, aside from the medical and ethical benefit, save easily the amount of money to compensate for the increased screening expenses for several thousands of women. Implementation of a risk-based IAP will not cover all colonized women and there will be more cases of early-onset disease. Besides, more women will receive antibiotics for risk factors that might not be caused by GBS. Thus, higher risk for bacterial resistance and anaphylactic reactions might be found, which may also result in higher cost.

In the future, the implementation of a rapid PCR-based intrapartum screening might improve sensitivity and specificity of GBS-screening at time of delivery and, therefore, increase effectiveness of the screening-based strategy $[11,18]$. Furthermore, an effective GBS vaccination is expected to be available in $5-10$ years which is likely to replace all other preventive strategies.

In conclusion, a screening-based strategy should be favored despite higher costs in first place. In the future, cheaper and more rapid testing should be developed. Generally, an intrapartum antibiotic prophylaxis is justified concerning a prevalence rate of $21 \%$ and an incidence of early-onset disease of 1.2/1000 live births.

\section{References}

[1] AAP. Revised guidelines for prevention of early-onset group B streptococcal (GBS) infection. American Academy of Pediatrics Committee on infectious diseases and committee on fetus and newborn. Pediatrics. 1997;99: 489-96.

[2] ACOG. ACOG committee opinion. Prevention of earlyonset group B streptococcal disease in newborns. Number 173-June 1996. Committee on obstetric practice.
American College of Obstetrics and Gynecologists. Int J Gynaecol Obstet. 1996;54:197-205.

[3] ACOG. ACOG committee opinion: number 279, December 2002. Prevention of early-onset group B streptococcal disease in newborns. Obstet Gynecol. 2002;100:1405-12.

[4] CDC. Prevention of perinatal group B streptococcal disease: a public health perspective. Centers for disease control and prevention. MMWR Recomm Rep. 1996;45:1-24.

[5] Baker C, E.M. Group B streptococcal infections. In: Remington $\mathrm{J}$, Klein $\mathrm{J}$, editors. Infectious diseases of the fetus and newborn infant 4th ed. Philadelphia: WB Saunders, 1995;980-1054.

[6] Baker CJ, Barrett FF, Gordon RC, Yow MD. Suppurative meningitis due to streptococci of Lance field group B: a study of 33 infants. J Pediatr. 1973;82:724-9.

[7] Baker CJ, E.M. Group B streptococcal infections. In: Remington J, Klein JO, editors, 1990.

[8] Boyer KM, Gotoff SP. Prevention of early-onset neonatal group B streptococcal disease with selective intrapartum chemoprophylaxis. N Engl J Med. 1986;314:1665-9.

[9] Colbourn TE, Asseburg C, Bojke L, Philips Z, Welton NJ, Claxton K, et al. Preventive strategies for group B streptococcal and other bacterial infections in early infancy: cost effectiveness and value of information analyses. $\mathrm{Br}$ Med J. 2007;335:655.

[10] Easmon CS, Hastings MJ, Neill J, Bloxham B, Rivers RP. Is group $B$ streptococcal screening during pregnancy justified? Br J Obstet Gynaecol. 1985;92:197-201.

[11] Gavino M, Wang E. A comparison of a new rapid real-time polymerase chain reaction system to traditional culture in determining group B streptococcus colonization. Am J Obstet Gynecol. 2007;197:388.e1-e4.

[12] Gibbs RS, Schrag S, Schuchat A. Perinatal infections due to group B streptococci. Obstet Gynecol. 2004;104(5 Pt 1): 1062-76.

[13] Grischke EM, Kaufmann M, Rabe T, Pohl S, Hingst V, Bastert G. [B-streptococci in obstetrics - risks and consequences of maternal colonization and neonatal contamination]. Geburtshilfe Frauenheilkd. 1992;52:335-9.

[14] Gynaecologists RCOGa. Prevention of early onset neonatal group B streptococcal disease. RCOG guideline no. 36. London, UK, 2003.

[15] Lancefield RC, HR. The serological differentiation of pathogenic strains of hemolytic streptococci from parturient women. J Exp Med. 1938;61:335-49.

[16] Martius J, HU, Roos R. Prophylaxe der Neugeborenensepsis (frühe Form) durch Streptokokken der Gruppe B. Deutsche Gesellschaft für Gynäkologie und Geburtshilfe DGGG, Leitlinie, 2004.

[17] McCracken GH Jr. Group B streptococci: the new challenge in neonatal infections. J Pediatr. 1973;82:703-6.

[18] Puopolo KM, Madoff LC, Eichenwald EC. Early-onset group B streptococcal disease in the era of maternal screening. Pediatrics. 2005;115:1240-6.

[19] Renner R, Holzgreve W, Nars P, Hösli I, Schmid S, Surbek D. Efficacy of a screening-strategy for the prevention of early-onset group B-streptococcus sepsis in newborns. J Perinat Med. 2006;34:32-38.

[20] Schrag S, Gorwitz R, Fultz-Butts K, Schuchat A. Prevention of perinatal group $B$ streptococcal disease. Revised guidelines from CDC. MMWR Recomm Rep. 2002;51: 1-22.

[21] Schrag SJ, Zell ER, Lynfield R, Roome A, Arnold KE, Craig AS, et al. A population-based comparison of strategies to 
prevent early-onset group B streptococcal disease in neonates. N Engl J Med. 2002;347:233-9.

[22] Schrag SJ, Zywicki S, Farley MM, Reingold AL, Harrison LH, Lefkowitz LB, et al. Group B streptococcal disease in the era of intrapartum antibiotic prophylaxis. N Engl J Med. 2000;342:15-20.

[23] Shah V, OA, Canadian Task Force on preventive health care. Prevention of early onset group B streptococcal infections in the newborn: systematic review and recommendations. CTFPHC technical report 01-6. London, ON: Canadian Taskforce, 2001.

[24] Stan CM, Boulvain M, Bovier PA, Auckenthaler R, Berner $\mathrm{M}$, Irion $\mathrm{O}$. Choosing a strategy to prevent neonatal earlyonset group B streptococcal sepsis: economic evaluation. Br J Obstet Gynaecol. 2001;108:840-7.

[25] Surbek D, Gross A, Seydoux J, Honegger C, Irion O, Drack G. Prophylaxe der early-onset-Neugeborenensepsis durch
Streptokokken der Gruppe B. Schweizerische Gesellschaft für Gynäkologie und Geburtshilfe SGGG, Expertenbrief, 2006.

[26] Surbek D, Pavic N, Almendral AC. Neonatal streptococciB sepsis: Incidence and risk factors. Arch Gynecol Obstet. 1995;257:148.

[27] Trijbels-Smeulders MA, Kollee LA, Adriaanse AH, Kimpen JL, Gerards LJ. Neonatal group B streptococcal infection: incidence and strategies for prevention in Europe. Pediatr Infect Dis J. 2004;23:172-3.

[28] Zangwill KM, Schuchat A, Wenger JD. Group B streptococcal disease in the United States, 1990: report from a multistate active surveillance system. MMWR CDC Surveill Summ. 1992;41:25-32.

Received May 27, 2008. Revised July 24, 2008. Accepted September 1, 2008. Previously published online October 31, 2008. 